\title{
PENGARUH RASA TIDAK AMAN BEKERJA TERHADAP SUBJECTIVE WELL-BEING DAN KUALITAS TIDUR DENGAN JOB EMBEDDEDNESS SEBAGAI MODERATOR
}

\author{
Theresia Meirosa Purba ${ }^{1}$ dan P. Tommy Y.S. Suyasa ${ }^{2}$ \\ ${ }^{1}$ Fakultas Psikologi, Universitas Tarumanagara Jakarta \\ Email: theresiameirosa@gmail.com \\ ${ }^{2}$ Fakultas Psikologi, Universitas Tarumanagara Jakarta \\ Email: tommys@fpsi.untar.ac.id
}

\begin{abstract}
ABSTRAK
Perubahan adalah suatu hal yang tidak terelakkan. Perubahan yang terjadi dalam organisasi bahkan disebut dapat menjadi salah satu sumber stress pada karyawan. Adanya gejala stress yang dialami karyawan tampak dari rasa tidak aman mengenai masa depan ataupun kelanjutan pekerjaannya. Bahkan rasa tidak aman bekerja diprediksi dapat berpengaruh terhadap kondisi emosi dan kualitas tidur karyawan. Dengan mengembangkan penelitian terdahulu, penelitian ini bertujuan mengidentifikasi pengaruh dari rasa tidak aman bekerja terhadap subjective well-being dan kualitas tidur pada karyawan Perusahaan X, dengan job embeddedness sebagai variabel moderator. Sebagai suatu gejala stress, rasa tidak aman bekerja (job insecurity) diartikan sebagai ancaman kehilangan pekerjaan yang dirasakan individu serta rasa khawatir yang berkaitan dengan ancaman tersebut. Dampak dari rasa tidak aman tersebut tampak pada subjective well-being yang diartikan sebagai penilaian keseluruhan individu terhadap pengalaman emosional, serta tampak pula pada kualitas tidur, yaitu aspek kuantitatif dan subyektif dari pengalaman tidur individu. Job embeddedness sebagai moderator didefinisikan sebagai faktor-faktor yang mempengaruhi keputusan seseorang untuk bertahan pada pekerjaan dan organisasi atau perusahaan. Penelitian ini berbentuk studi kuantitatif non-eksperimental dengan melibatkan 110 karyawan tetap dari Perusahaan X. Pengambilan data dilakukan melalui metode survey dengan menyebarkan e-form. Kemudian data dianalisis dengan metode regresi linear melalui program SPSS 24.0. dan menunjukkan hasil di mana secara umum job embeddedness tidak menunjukkan peran sebagai moderator pada pengaruh dari rasa tidak aman bekerja terhadap subjective well-being maupun kualitas tidur. Namun demikian, job embeddedness pada level tertentu akan menunjukkan peran sebagai moderator.
\end{abstract}

Kata kunci: job embeddedness, rasa tidak aman bekerja, subjective well-being, kualitas tidur.

ABSTRACT

Change is inevitable Changes that occur in an organization might even be a stressor for employees. One symptom of stress experienced by employees is the insecurity about the future or the continuation of their employment. This feeling of work insecurity is predicted to affect the emotional condition and quality of sleep of employees. By improving on previous research, this study aims to identify the effect of work insecurity on subjective well-being and sleep quality in Company X employees, with job embeddedness as a moderating variable. As a symptom of stress, job insecurity is defined as the threat of job loss felt by individuals as well as the worry associated with said threat. The impact of insecurity on subjective well-being is defined as an overall individual assessment of emotional experience, which is reflected on the quality of sleep, namely the quantitative and subjective aspects of individual sleep experience. Job embeddedness as the moderator is defined as the factors that influence a person's decision to stay with the job and organization or company. This research is a non-experimental quantitative study involving 110 employees from Company X. Data was collected through a survey by distributing e-forms. Then, the data were analyzed using linear regression method on SPSS 24.0. which shows that, in general, job embeddedness does not serve as moderator of the influence of work insecurity on subjective well-being and sleep quality. However, job embeddedness, at a certain level serves as moderator.

Keywords: job embeddedness, work insecurity, subjective well-being, sleep quality. 


\section{PENDAHULUAN}

\section{Latar Belakang}

Perubahan pada organisasi merupakan salah satu fenomena yang umum terjadi. Hal tersebut tampak dari hasil survei yang dilakukan oleh Deloitte Global Human Capital pada tahun 2016 dan 2017, yang menemukan bahwa tren yang paling utama di tahun 2016 adalah dalam aspek desain organisasi yang bertujuan agar perusahaan mampu lebih cepat bergerak dan lebih fungsional (Deloitte University Press, 2016). Tidak jauh berbeda, tren utama tahun 2017 berfokus pada pembentukan organisasi masa depan (Deloitte University Press, 2017). Tuntutan perubahan tersebut juga dialami oleh Perusahaan X, sebuah perusahaan swasta multinasional yang bergerak dalam bidang manufaktur dan distribusi produk kebutuhan perawatan kecantikan dan kebersihan rumah tangga. Meski tidak terjadi perubahan yang masif, Perusahaan X tampak sering melakukan reorganisasi dalam dua tahun terakhir, khusunya di kantor pusat, sebagai salah satu upaya untuk mengembangkan bisnis. Perubahan organisasi yang terlihat adalah berupa adanya mutasi karyawan antar departemen, sampai dengan adanya restrukturisasi yang mengakibatkan karyawan kehilangan wewenang dalam satu tugas tertentu.

Sebagai salah satu karakteristik kehidupan kerja, adanya perubahan di organisasi dapat memiliki pengaruh yang berbeda-beda terhadap masing-masing karyawan. Secara objektif, perubahan yang terjadi dapat mempengaruhi persepsi subjektif karyawan bahwa pekerjaannya saat ini berada dalam ketidakpastian (De Witte, Vander Elst, \& De Cuyper, in press; Reisel, 2003, dalam Vander Elst et al., 2016). Persepsi subjektif tersebut tampak dari penilaian yang berbeda dari masing-masing karyawan di Perusahaan X. Salah satu hal yang membedakan penilaian tersebut dapat dilihat berdasarkan masa kerja dari karyawan yang bersangkutan. Adapun Perusahaan X memiliki karyawan dengan rata-rata masa kerja yang tergolong cukup lama, yaitu 11 tahun. Lamanya masa kerja tersebut terlihat tampak mempengaruhi persepsi karyawan terhadap perubahan. Berdasarkan wawancara singkat yang dilakukan, seorang karyawan dengan masa kerja satu tahun merasa tidak keberatan saat ia harus dimutasi dari Kantor Pusat ke kantor cabang. Namun berbeda halnya dengan karyawan lain dengan masa kerja sembilan tahun, banyaknya perubahan organisasi di Perusahaan $\mathrm{X}$ justru membuat ia khawatir dan memiliki bayangan akan dipindahkan ke bagian yang kurang sesuai dengan minatnya.

Fenomena perubahan di Perusahaan X yang dapat dikategorikan sebagai sumber stres pada akhirnya menjadi penyebab timbulnya rasa tidak aman bekerja (job insecurity). Kurangnya rasa kontrol dan prediktabilitas selama kondisi perubahan atau ketidakpastian seperti downsizing, layoffs, maupun bentuk perubahan lainnnya berkaitan dengan rasa tidak aman bekerja yang lebih kuat (Armstrong-Stassen, 2005; Østhus, 2007; Probst \& Lawler, 2006, dalam Keim et al., 2014). Terdapat penelitian terdahulu yang dilakukan oleh Allen et al. (2016) mengenai job embeddedness pada karyawan. Konstruk ini menekankan bahwa semakin besar koneksi seseorang dengan organisasi dan komunitasnya, maka akan semakin tinggi kemungkinan dia bertahan di organisasi (Holtom et al., 2006). Hanya saja, berbeda dengan kebanyakan penelitian mengenai dampak positif job embeddedness, Allen menekankan pada sisi gelap (Allen. et al., 2016). Adapun job embeddedness diperkirakan berperan sebagai moderator pada pengaruh rasa tidak aman bekerja terhadap kelelahan emosional dan kualitas tidur, di mana ketika karyawan lebih embed (merasakan kelekatan), tingginya rasa tidak aman bekerja akan memiliki dampak berupa kelelahan secara emosional dan kualitas tidur yang buruk. Efek moderasi terjadi karena job embeddedness dapat memberikan efek buffering yang mencegah kejadian negatif menimbulkan turnover pada karyawan. 
Secara teroretis, kondisi tersebut dijelaskan melalui Consevation of Resources (COR) Theory yang menerangkan bahwa karyawan dengan job embeddedness tinggi cenderung berusaha mempertahankan pekerjaan yang dipandang sebagai aset atau hal yang bernilai, karena kehilangan pekerjaan merupakan hal yang tidak menyenangkan baginya (Kiazad et al., 2015, dalam Allen. et al., 2016). Dengan demikian, karyawan tersebut akan melakukan cara untuk melindungi pekerjaannya, dan salah satu caranya adalah dengan bertahan dalam kondisi negatif (misalnya kondisi yang menimbulkan rasa tidak aman bekerja). Pada akhirnya, kondisi tidak aman bekerja dalam bentuk ancaman kehilangan pekerjaan yang dihadapi secara terus-menerus (karena karyawan bertahan dalam pekerjaannya) akan mengancam kesejahteraan dan kesehatan karyawan, dan berdampak pula pada buruknya kesejahteraan psikologis maupun fisik, baik dalam bentuk kondisi tidak sejahtera, maupun kualitas tidur yang buruk (Hobfoll, 2002, dalam Allen et al., 2016).

Adapun hasil penelitian yang dilakukan oleh Allen (2016) menunjukkan bahwa job embeddedness gagal berperan sebagai moderator dalam hubungan antara rasa tidak aman bekerja karyawan terhadap kelelahan emosionalnya. Namun demikian, hasil tersebut berbeda dengan beberapa penelitian lainnya yang menunjukkan bahwa terdapat hubungan positif antara sumber stres kerja (salah satunya adalah job security) dengan penerimaan secara kognitif, khususnya pada individu dengan tingkat job embeddedness rendah (Chetty et al., 2016). Selain itu, terbukti juga bahwa rasa tidak aman bekerja dan kelelahan emosional memiliki hubungan yang positif pada individu dengan embeddedness yang tinggi (Lawrence \& Kacmar, 2017).

Tidak terbuktinya peran job embeddedness sebagai moderator dalam hubungan antara rasa tidak aman bekerja dengan kelelahan emosional pada penelitian Allen et al (2016) dijelaskan karena rasa tidak aman bekerja cenderung dirasakan secara samar oleh partisipan penelitian. Kondisi yang samar tersebut selanjutnya kurang menunjukkan suatu kondisi ancaman terhadap karyawan dibandingkan kondisi negatif lain yang dirasakan secara langsung. Lebih lanjut lagi dijelaskan bahwa kurangnya kondisi mengancam yang dirasakan partisipan adalah dikarenakan fenomena rasa tidak aman bekerja belum dijelaskan secara rinci, di mana partisipan berasal dari berbagai bidang pekerjaan tanpa kesamaan kondisi kerja yang terbilang negatif. Dengan demikian, belum tampak fenomena yang menimbulkan ancaman bagi partisipan yang selanjutnya dapat menimbukan rasa tidak aman bekerja (Allen et al., 2016).

Untuk melihat pengaruh terhadap rasa tidak aman bekerja, Allen et al. (2016) menggunakan komponen afektif dari well-being dalam meneliti kesejahteraan karyawan, yaitu emotional exhaustion. Namun demikian, dikarenakan penelitian tersebut masih belum mengukur komponen well-being secara keseluruhan, penelitian ini ingin menggunakan konsep subjective well-being dari Watson, Clark, \& Tellegen (1988) yang mengukur positive affect dan negative affect sehingga dapat melengkapi konsep well-being yang digunakan Allen. Hal ini didasarkan adanya studi longitudinal yang menunjukkan bahwa individu dengan subjective well-being yang tinggi menunjukkan kinerja yang lebih baik serta sukses dalam karirnya (Peterson et al., 2011). Selain itu, karyawan yang optimis dan penuh harapan memiliki kinerja yang lebih baik dibandingkan rekannya yang pesimis. Namun demikian, konsep subjective well-being dari Watson, Clark, \& Tellegen (1988) sendiri masih dapat dikatakan belum lengkap, sehingga kualitas tidur sebagai komponen fisik tetap digunakan untuk melihat kesejahteraan karyawan secara lebih utuh.

Berdasarkan paparan tersebut, penelitian ini bertujuan untuk mengkaji lebih lanjut mengenai peran job embeddedness sebagai moderator, terlebih dengan adanya perbedaan hasil antara penelitian sebelumnya. Selain itu, penelitian ini juga bermaksud ingin melengkapi hasil 
penelitian Allen et al. (2016) dengan menambahkan komponen well-being yang lebih komprehensif, memfokuskan penelitian pada perusahaan yang menunjukkan fenomena yang menimbulkan rasa tidak aman bekerja, serta untuk melihat bagaimana pengaruh rasa tidak aman bekerja terhadap subjective well-being dan kualitas tidur pada karyawan Perusahaan $\mathrm{X}$ dengan adanya peran job embeddedness sebagai moderator.

\section{Rumusan Masalah}

Adapun penelitian ini mencoba menjawab rumusan masalah antara lain: (1) apakah job embeddedness berperan sebagai moderator dalam hubungan antara rasa tidak aman bekerja dengan subjective well-being pada karyawan Perusahaan $\mathrm{X}$ dan (2) apakah job embeddedness berperan sebagai moderator dalam hubungan antara rasa tidak aman bekerja dengan kualitas tidur pada karyawan Perusahaan X?

\section{METODE PENELITIAN}

Penelitian ini merupakan penelitian kuantitatif non-eksperimental yang melibatkan 110 orang karyawan tetap di Perusahaan X sebagai partisipan. Teknik pengambilan sampel yang digunakan adalah non-probability sampling, secara spesifik yaitu teknik accidental sampling dimana pemilihan partisipan didasarkan pada ketersediaan akses terhadap partisipan dan kondisi di lapangan.

Pengambilan data dilakukan dengan menyebar lembar kuisioner atau link e-form. Adapun peneliti menggunakan alat ukur Positive and Negative Affect Scale (PANAS) yang dikembangkan oleh Watson dan Clark (1988) untuk mengukur subjective well-being. Alat ukur ini terdiri atas 33 butir item yang menggunakan skala Likert, dengan skor koefisien internal consistency sebesar 0.855. Selanjutnya, untuk mengukur kualitas tidur, peneliti menggunakan alat ukur alat ukur sleep quality index yang diadaptasi dari The Pittsburgh Sleep Quality Index (PSQI) yang dikembangkan oleh Buysse et al. (1989). Alat ukur tersebut terdiri 19 komponen pertanyaan dengan skor koefisien internal consistency sebesar 0.607.

Pengukuran variabel job embeddedness dilakukan dengan menggunakan skala Job Embeddedness yang diadaptasi dari skala oleh Mitchell et al. (2001), khususnya aspek organisasi. Adapun aspek organisasi dipilih dikarenakan penelitian Allen et al. (2016) membuktikan bahwa on-the-job embeddedness masih lebih relevan terhadap perasaan "terjebak" dalam kondisi kerja yang negatif dibandingkan dengan off-the-job embeddedness. Selain itu, onthe-job embeddedness juga disebut lebih dapat mempertahankan karyawan dibandingkan dengan off-the-job embeddedness (Purba, 2016). Alat ukur ini terdiri dari 23 item pertanyaan dengan skor koefisien internal consistency sebesar 0.850. Adapun untuk mengukur rasa tidak aman bekerja, peneliti menggunakan adaptasi dari Job Insecurity Questionnaire (JIQ) yang dikembangkan oleh De Witte (2010), dengan total jumlah pernyataan sebanyak 11 item dan skor koefisien internal consistency sebesar 0.827.

\section{HASIL DAN PEMBAHASAN}

Analisis data pada penelitian ini dilakukan secara bertahap untuk melihat apakah job embeddedness memiliki peran sebagai moderator dalam pengaruh rasa tidak aman bekerja terhadap subjective wel-being dan kualitas tidur karyawan pada Perusahaan X. Adapun peneliti menggunakan Pearson Correlation atau metode multiple regression dengan bantuan program SPSS. Analisis data tahap pertama dengan hasil $\mathrm{B}=-0.01$ dengan $\mathrm{p}=0.21>0.05$ menunjukkan bahwa tidak terdapat hubungan signifikan antara rasa tidak aman bekerja dan subjective well- 
being pada partisipan. Uji korelasi dengan Pearson Correlation yang dilakukan terhadap masingmasing dimensi rasa tidak aman bekerja dan masing-masing dimensi subjective well-being menunjukkan terdapat korelasi signifikan dengan alpha 0.01 pada rasa tidak aman bekerja dimensi cognitive dengan dimensi positive affect $(\mathrm{r}=-0.19$ dan $\mathrm{p}=0.04)$. Selain itu, terdapat hubungan signifikan antara rasa tidak aman bekerja dimensi affective dengan dimensi negative affect $(\mathrm{r}=0.40$ dan $\mathrm{p}=0.00$, alpha 0.05).

Pada tahap kedua, melalui uji regresi linier diperoleh nilai $\mathrm{B}=0.50$ dengan $\mathrm{p}=0.00<0.05$, dan dapat disimpulkan bahwa terdapat hubungan signifikan antara job embeddedness dan subjective well-being pada partisipan. Selanjutnya, pengolahan data pada tahap ketiga menunjukkan hasil $\mathrm{B}=-0.02$ dan $\mathrm{p}=0.82>0.05$, di mana berarti tidak terdapat hubungan signifikan antara interaksi job embeddedness dan rasa tidak aman bekerja terhadap subjective well-being. Sehingga berdasarkan ketiga tahapan uji hipotesis tersebut disimpulkan bahwa secara umum, job embeddedness tidak terbukti berperan sebagai moderator dalam pengaruh rasa tidak aman bekerja terhadap subjective well-being.

Seperti halnya dengan penelitian yang menunjukkan hasil berbeda dengan yang dilakukan oleh Allen et al. (2016), pada penelitian ini, peneliti berusaha menganalisis peran job embeddedness sebagai moderator pada tingkatan tertentu dalam hubungan kedua varibel serta masing-masing dimensinya. Setelah dikategorikan menjadi job embeddedness rendah (berdasarkan z-score job embeddedness, dengan Mean < 0.00) dan tinggi (berdasarkan z-score job embeddedness, dengan Mean > 0.00), hasil uji regresi antara rasa tidak aman bekerja dan subjective well-being secara keseluruhan pada individu dengan job embeddedness rendah $(\mathrm{p}=0.15)$ maupun tinggi $(\mathrm{p}=0.69)$ menunjukkan hasil yang tidak signifikan ( $\mathrm{p}>0.05$ ). Namun job embeddedness akan berperan sebagai moderator pada hubungan antardimensi tertentu. Pertama, job embeddedness rendah akan berperan sebagai moderator pada pengaruh antara rasa tidak aman bekerja dimensi cognitive terhadap positive affect $(\mathrm{p}=0.04<0.05)$. Artinya, pada individu yang tidak terlalu memiliki kelekatan dengan pekerjaannya, emosi positif yang dialami individu tersebut akan dapat menurunkan pikiran negatifnya terkait persepsi atau pemahaman kemungkinan kehilangan pekerjaan. Namun, pada individu yang memiliki kelekatan dengan pekerjaannya, belum tentu emosi positif yang dialaminya akan dapat menurunkan pikiran negatif tersebut. Kedua, job embeddedness tinggi akan berperan sebagai moderator pada pengaruh rasa tidak aman bekerja dimensi cognitive terhadap negative affect $(\mathrm{p}=0.01<0.05)$. Artinya, semakin tinggi persepsi atau pemahanan individu mengenai kemungkinan akan kehilangan pekerjaan, maka individu dengan kelekatan kerja yang tinggi akan semakin merasakan tekanan subjektif dan keterikatan yang tidak menyenangkan. Namun, kondisi emosi yang negatif tersebut belum tentu akan dialami oleh individu yang memiliki kekatan yang rendah pada pekerjaannya, saat ia memahami akan adanya kemungkinan kehilangan pekerjaan.

Selain melihat pengaruh rasa tidak aman bekerja terhadap subjective well-being dengan job embeddedness sebagai moderator, penelitian ini juga bertujuan melihat bagaimana pengaruh rasa tidak aman bekerja terhadap kualitas tidur. Analisis tahap pertama dengan regresi linier menunjukkan hasil $\mathrm{B}=0.24$ dengan $\mathrm{p}=0.01<0.05$, sehingga disimpulkan bahwa terdapat hubungan signifikan antara rasa tidak aman bekerja dan kualitas tidur pada partisipan. Analisis terhadap masing-masing dimensi menunjukkan bahwa kedua dimensi rasa tidak aman bekerja memiliki pengaruh terhadap kualitas tidur dengan alpha 0.01 pada dimensi cognitive $(\mathrm{r}=-0.19$ dan $\mathrm{p}=0.03)$, dan alpha 0.01 pada dimensi affective $(\mathrm{r}=-0.21$ dan $\mathrm{p}=0.02$, alpha 0.01). 
Pada tahap kedua, dilakukan uji korelasi antara job embeddedness dan kualitas tidur dengan menggunakan regresi linier, dan diperoleh hasil $\mathrm{B}=0.19$ dengan $\mathrm{p}=0.03<0.05$, sehingga disimpulkan bahwa terdapat hubungan signifikan antara job embeddedness dan kualitas tidur pada partisipan. Selanjutnya, tahap ketiga melalui uji regresi menunjukkan hasil berupa $\mathrm{B}=-0.07$ dan $\mathrm{p}=0.41>0.05$, yang berarti bahwa tidak terdapat hubungan signifikan antara interaksi job embeddedness dan rasa tidak aman bekerja terhadap kualitas tidur. Dengan demikian, dapat disimpulkan bahwa secara umum, job embeddedness tidak terbukti berperan sebagai moderator dalam pengaruh dari rasa tidak aman bekerja terhadap kualitas tidur. Namun demikian, jika dianalisis berdasarkan kategori job embeddedness tinggi dan rendah, diperoleh hasil berupa hubungan yang signifikan antara rasa tidak aman bekerja dengan kualitas tidur pada individu dengan job embeddedness tinggi $(\mathrm{p}=0.05)$ dan tidak signifikan pada job embeddedness rendah $(\mathrm{p}=0.14)$. Hal ini menunjukkan bahwa job embeddedness pada tingkat yang tinggi akan berperan sebagai moderator pada pengaruh rasa tidak aman bekerja terhadap kualitas tidur. Artinya, semakin individu merasakan ancaman dan kekhawatiran kehilangan pekerjaan, maka individu dengan job embeddedness atau kelekatan kerja yang tinggi akan semakin mengalami kualitas tidur yang buruk. Namun, kondisi kualitas tidur yang buruk belum tentu dialami oleh individu dengan job embeddedness atau kelekatan yang rendah pada pekerjaannya.

\section{KESIMPULAN DAN SARAN}

Dari hasil yang telah dipaparkan sebelumnya, dapat ditarik kesimpulan sebagai berikut. Secara umum, job embeddedness tidak terbukti berperan sebagai moderator dalam pengaruh dari rasa tidak aman bekerja terhadap subjective well-being maupun terhadap kualitas tidur, sehingga dapat pula disimpulkan bahwa hasil penelitian ini tidak menjawab hipotesis penelitian secara umum. Meski demikian, job embeddedness pada taraf tinggi akan menunjukkan peran sebagai moderator pada pengaruh rasa tidak aman bekerja (dimensi cognitive) terhadap subjective wellbeing (dimensi negative affect) maupun kualitas tidur. Artinya, semakin tinggi persepsi atau pemahanan individu mengenai kemungkinan akan kehilangan pekerjaan, maka individu dengan kelekatan kerja yang tinggi akan semakin merasakan tekanan subjektif dan keterikatan yang tidak menyenangkan. Selain itu, job embeddedness pada taraf rendah juga akan menunjukkan peran sebagai moderator pada pengaruh rasa tidak aman bekerja (dimensi affective) terhadap subjective well-being (dimensi positive affect). Artinya, pada individu yang tidak terlalu memiliki kelekatan dengan pekerjaannya, emosi positif yang dialami individu tersebut akan dapat menurunkan pikiran negatifnya terkait persepsi atau pemahaman kemungkinan kehilangan pekerjaan.

Adapun hasil penelitian ini sejalan dengan hasil penelitian oleh Allen et al. (2016), di mana job embeddedness tidak terbukti berperan sebagai moderator dalam pengaruh rasa tidak aman bekerja terhadap emotional exhaustion. Hal tersebut dikarenakan rasa tidak aman bekerja cenderung masih dirasakan secara samar dan kurang menunjukkan ancaman dibandingkan kondisi lain (misalnya perlakuan buruk dari atasan/abusive supervision) yang dapat dirasakan secara langsung dan membahayakan (Allen et al., 2016). Hanya saja, hasil penelitian ini masih sejalan dengan sejumlah hasil penelitian lainnya (Lawrence \& Kacmar, 2017) yang menunjukkan hasil bahwa rasa tidak aman bekerja dan kelelahan emosional memiliki hubungan yang positif pada individu dengan embeddedness yang tinggi.

Terkait dengan hasil penelitian ini, saran praktis yang diajukan oleh peneliti adalah adanya upaya lebih dari perusahaan untuk mengurangi akibat negatif yang diakibatkan oleh rasa tidak aman bekerja. Adapun rasa tidak aman bekerja yang timbul akibat perubahan di organisasi merupakan 
hal yang dapat menjadi bermasalah dikarenakan sifatnya yang tidak dapat diprediksi dan dikontrol. Efek negatif dari kondisi yang sulit diprediksi tersebut dapat dikurangi melalui tiga cara, yaitu melalui adanya komunikasi yang lebih berhati-hati dan tetap terbuka, mengikutsertakan karyawan dalam proses pengambilan keputusan, dan dengan meningkatkan keadilan organisasional (organisational justice). Secara lebih detail, cara tersebut dijelaskan melalui penelitian yang menyarankan bahwa melakukan komunikasi terbuka dan jelas mengenai perubahan organisasi terbukti efektif dalam mengurangi rasa tidak aman pada diri karyawan. Selain itu, komunikasi yang terbuka, jujur, dan adanya informasi yang disampaikan secara dini dapat meningkatkan rasa prediktabilitas dan kontrol terhadap kejadian di masa depan. Komunikasi yang demikian juga mampu meningkatkan persepsi karyawan bahwa ia dihormati dan dianggap (Schweiger \& DeNisi, 1991, dalam De Witte, 2005).

\section{Ucapan Terima Kasih (Acknowledgement)}

Peneliti mengucapkan terima kasih atas dukungan dan bantuan yang telah diterima selama berjalannya penelitian ini, terutama pada manajemen Perusahaan $\mathrm{X}$ yang telah memberi izin untuk dilaksanakannya penelitian. Begitu pula dengan 110 orang karyawan Perusahaan $\mathrm{X}$ yang telah bersedia berpartisipasi dalam penelitian ini.

\section{REFERENSI}

Alarco, B., De Cuyper, N., \& De Witte, H. (2012). The relationship between job insecurity and well-being among Peruvian workers. Romanian Journal of Applied Psychology, 14(2), 43

Allen, D. G., Peltokorpi, V., \& Rubenstein, A. L. (2016). When "embedded" means "stuck": Moderating effects of job embeddedness in adverse work environments. Journal of Applied Psychology, 101(12), 1670-1686. http://dx.doi.org/10.1037/apl0000134

Baron, R. M. and Kenny, D. A. 1986. The moderator-mediator variable distinction in social psychological research: conceptual, strategic, and statistical considerations. Journal of Personality and Social Psychology, 51(6), 1173-1182.

Besich, J. (2005). Job Embeddedness versus Traditional Models of Voluntary Turn over: A Test of Voluntary Turnover Prediction (Doctoral Dissertation). Denton, Texas: University of North Texas.

Bosman, J., Buitendach, J., \& Rothman, S. (2005). Work locus of control and dispositional optimism as antecedents to job insecurity. SA Journal of Industrial Psychology, 31(4). doi:10.4102/sajip.v31i4.217

Burgard, S. \& Ailshire, J. (2008). Putting work to bed: stressful experiences on the job and sleep quality. Retrieved from https://www.psc.isr.umich.edu/pubs/pdf/rr08-652.pdf

Buysse, D. J., Reynolds, C. F., III, Monk, T. H., Berman, S. R., \& Kupfer, D. J. (1989). The Pittsburgh Sleep Quality Index: A new instrument for psychiatric practice and research. Psychiatry Research, 28, 193-213. http://dx.doi.org/10.1016/0165-1781(89)90047-4

Chetty, P. J. J., Coetzee, M., Ferreira, N. (2016). Sources of job stress and cognitive receptivity to change: The moderating role of job embeddedness. South African Journal of Psychology, 46(1), 101 - 113. https://doi.org/10.1177/0081246315591308 
Crossley, C., et al. (2007). Development of a global measure of job embeddedness and integration into a traditional model of voluntary turnover. Journal of Applied Psychology, 96(6), 1316.

Clinton, M., et al. (2012). Job Embeddedness: A new attitudinal measure. Journal of Selection \& Assessment, 20(1), $111-117$

De Witte, H. (2005). Job insecurity: Review of the international literature on definitions, prevalence, antecedents and consequences. SA Journal of Industrial Psychology, 31(4). doi:10.4102/sajip.v31i4.200

De Witte H., Vander Elst T., De Cuyper N. (2015). Job Insecurity, Health and Well-Being. Dordrecht: Springer

Deloitte University Press. (2016). Global Human Capital Trends 2016. The New Organization: Different by Design. Retrieved from https://www2.deloitte.com/content/dam/Deloitte/global/Documents/HumanCapital/gx-dupglobal-human-capital-trends-2016.pdf

Deloitte University Press. (2017). 2017 Deloitte Global Human Capital Trends. Rewriting The Rules for The Digital Age. Retrieved from https://www2.deloitte.com/content/dam/Deloitte/us/Documents/human-capital/hc-2017global-human-capital-trends-us.pdf

Diener, E., Heintzelman, S. J., Kushlev, K., Tay, L., Wirtz, D., Lutes, L. D., \& Oishi, S. (2017). Findings all psychologists should know from the new science on subjective well-being. Canadian Psychology/Psychologie canadienne, 58(2), 87-104. http://dx.doi.org/10.1037/cap0000063

Erdogan, B., Bauer, T. N., Truxillo, D. M., \& Mansfield, L. R. (2012). Whistle while you work: A review of the life satisfaction literature. Journal of Management, 38(4), 1038-1083. http://dx.doi.org/10.1177/0149206311429379

Fischer, R., \& Boer, D. (2011). What is more important for national well-being: Money or autonomy? A meta-analysis of well-being, burnout, and anxiety across 63 societies. Journal of Personality and Social Psychology, 101(1), 164-184. http://dx.doi.org/10.1037/a0023663

Giosan, C. (2003). Predictors of job embeddedness. Psychology Society Bulletin, 1(1). New York : Cornell University.

Habeck \& Brickman. (2014). A common statistical misunderstanding in Psychology: Do we need normally distributed independent or dependent variables for linear regression to work? Retrieved from http://www.columbia.edu/cu/bnet/StatisticalFallacy_July2014.pdf

Halbesleben, J.R.B. and Wheeler, A.R. (2008). The relative roles of engagement and embeddedness in predicting job performance and intention to leave. Work \& Stress, 22, 242-256. http://dx.doi.org/10.1080/02678370 802383962

Holtom, B. C., T. R. Mitchell, \& T. W. Lee. (2006). Incerasing human and social capital by applying job embeddedness theory. Organization Dynamics,35(4), 316 - 331.

Huang, G. H., Niu, X., Lee, C., \& Ashford, S. J. (2012). Differentiating cognitive and affective job insecurity: Antecedents and outcomes. Journal of Organizational Behavior, 33, 752769. doi:10.1002/job.1815 
Hurlock, E. B. (1980). Developmental Psychology 5th Edition. New York: McGraw-Hill.

Julianto, Pramdia Arhando. (2017). Perusahaan Ritel Banyak Tutup, Apa yang Sebenarnya Terjadi? Retrieved from http://amp.kompas.com/ekonomi/read/2017/10/27/184542026/ perusahaan-ritel-banyak-tutup-apa-yang-sebenarnya-terjadi

Keim, A. C., Landis, R. S., Pierce, C. A., \& Earnest, D. R. (2014). Why do employees worry about their jobs? A meta-analytic review of predictors of job insecurity. Journal of Occupational Health Psychology, 19(3), 269-290. http://dx.doi.org/10.1037/a0036743

Kochkodin, Brandon. (2017). GE Ranks First in 2017 Downsizing After 12,000 More Job Cuts. Retrieved from https://www.bloomberg.com/news/articles/2017-12-07/ge-ranks-first-in2017-downsizing-after-12-000-more-job-cuts

Lawrence, E., \& Kacmar, K. (2017). Exploring the impact of job insecurity on employees' unethical behavior. Business Ethics Quarterly, 27(1), 39-70. doi:10.1017/beq.2016.58

Leupold, C. R., Ellis, L. E., \& Valle, M. (2013). Job embeddedness and retail pharmacists' intention to leave. The Psychologist-Manager Journal, 16(4), 197-216.

Mitchell, T. R. et al. (2001). Why people stay: Using job embeddedness to predict voluntary turnover. Academy of Management Journal, 44(6), 1102 - 112.

Peterson, S. J., Luthans, F., Avolio, B. J., Walumbwa, F. O. and Zhang, Z. (2011). Psychological Capital and Employee Performance: A Latent Growth Modeling Approach. Personnel Psychology, 64, 427-450. Doi:10.1111/J.1744-6570.2011.01215.X

Purba, D.E. (2016). Employee embeddedness and turnover intentions: exploring the moderating effects of commute time and family embeddedness. Makara Hubs-Asia, 19(1), 51-63

Riasudeen, S. \& Srinivasan, P.T. (2011). Predictors of organisational and job commitment in diverse organisation. Asia-Pacific Journal of Management Research and Innovation, 7(3), $188-197$

Shoss, M. K., Jiang, L., \& Probst, T. M. (2016). Bending without breaking: a two-study examination of employee resilience in the face of job insecurity. Journal of Occupational Health Psychology. Advance online publication. http://dx.doi.org/10.1037/ocp0000060

Slugoski, E. V. (2008). Employee Retention: Demographic Comparison of Job Embeddedness, Job Alternatives, Job Satisfaction, and Organizational Commitment (Doctoral Dissertation). Tempe, Arizona: University of Phoenix.

Sun, T., et al. (2011). The impact of psychological capital on job embeddedness and job performance among nurse: A structural equation approach. Journal of Advance Nursing, 68(1), 69-79.

Takawira, N., et al. (2014). Job embeddedness, work engagement and turnover intention of staff in a higher education institution: An exploratory study. SA Journal of Human Resource Management, 12(1), doi: 10.4102/sajhrm.v12i1.524

Vander Elst, T., Näswall, K., Bernhard-Oettel, C., De Witte, H., \& Sverke, M. (2016). The effect of job insecurity on employee health complaints: A within-person analysis of the explanatory role of threats to the manifest and latent benefits of work. Journal of Occupational Health Psychology, 21(1), 65-76. http://dx.doi.org/10.1037/a0039140 
Watson, D., Clark LA., \& Tellegen, A. (1988). Development and validation of brief measures of positive and negative affect - the Panas Scales. Journal of personality and social psychology, 54, 1063-70. 10.1037//0022-3514.54.6.1063. 